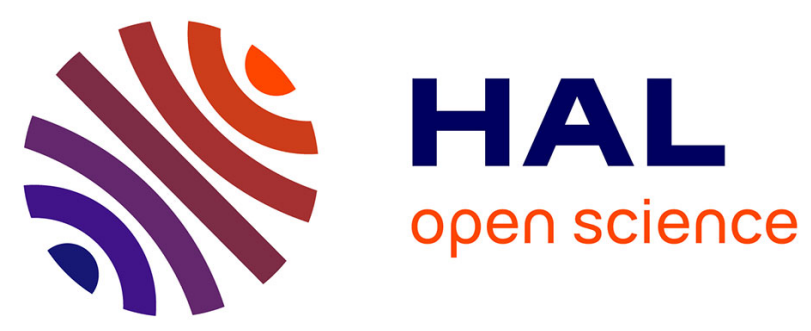

\title{
Improvement of the stability under illumination of a-Si:H films elaborated by ion-beam-assisted evaporation using a hydrogen-argon plasma
}

H. Rinnert, M. Vergnat, G. Marchal, A. Burneau

\section{- To cite this version:}

H. Rinnert, M. Vergnat, G. Marchal, A. Burneau. Improvement of the stability under illumination of a-Si:H films elaborated by ion-beam-assisted evaporation using a hydrogen-argon plasma. Journal of Applied Physics, 1998, 83 (2), pp.1103-1106. 10.1063/1.366800 . hal-02113433

\section{HAL Id: hal-02113433 \\ https://hal.science/hal-02113433}

Submitted on 28 Apr 2019

HAL is a multi-disciplinary open access archive for the deposit and dissemination of scientific research documents, whether they are published or not. The documents may come from teaching and research institutions in France or abroad, or from public or private research centers.
L'archive ouverte pluridisciplinaire HAL, est destinée au dépôt et à la diffusion de documents scientifiques de niveau recherche, publiés ou non, émanant des établissements d'enseignement et de recherche français ou étrangers, des laboratoires publics ou privés. 


\title{
Improvement of the stability under illumination of a-Si:H films elaborated by ion-beam-assisted evaporation using a hydrogen-argon plasma
}

\author{
H. Rinnert, ${ }^{\text {a) }}$ M. Vergnat, and G. Marchal \\ Laboratoire de Physique des Matériaux, U.R.A. au C.N.R.S. No. 155, Université Henri Poincaré Nancy 1, \\ B.P. 239, 54506 Vandoeuvre-lès-Nancy Cedex, France \\ A. Burneau \\ Laboratoire de Chimie Physique pour l'Environnement, U.M.R. au C.N.R.S. No. 9992, \\ Université Henri Poincaré Nancy 1, 405 rue de Vandoeuvre, 54506 Villers-lès-Nancy Cedex, France
}

(Received 16 September 1997; accepted for publication 12 October 1997)

\begin{abstract}
Hydrogenated amorphous silicon films were deposited by ion-beam-assisted evaporation using a hydrogen-argon plasma. The influence of the substrate temperature was studied. Light induced photoconductivity decay measurements showed that high stability materials can be obtained under well defined conditions. By combined infrared spectrometry and thermal desorption spectrometry experiments, it was demonstrated that microstructure has a great influence on the stability against light induced defects. (C) 1998 American Institute of Physics. [S0021-8979(98)05702-8]
\end{abstract}

\section{INTRODUCTION}

It is well known that hydrogen atoms incorporated in a-Si:H films during deposition saturate silicon dangling bonds and render the material suitable to electronic application by decreasing the density of defect states in the gap. But there is still considerable work to produce high quality a$\mathrm{Si}: \mathrm{H}$ films free from light induced instability (StaeblerWronski effect ${ }^{1}$ ). Even if there is still a lively debate to explain this effect it appears that weak $\mathrm{Si}-\mathrm{Si}$ bonds have an important role in the creation of defects. ${ }^{2}$

The glow-discharge decomposition of the silane gas method has become the most important method for the deposition of a-Si:H films and up to now the highest quality material has been prepared by this technique. However several attempts have been made to introduce hydrogen into evaporated a-Si films in a high vacuum chamber. Obtaining good quality $\mathrm{Si}-\mathrm{H}$ bonding required the production of atomic hydrogen by dissociation of molecules in a heated tungsten tube $^{3}$ or the use of an ion beam from a Kaufman type source. ${ }^{4,5}$ Such a technique presents the advantage of avoiding the use of toxic gas like silane. Moreover with ion-beamassisted evaporation, ion bombardment is essentially independent of silicon deposition, which allows easy control of the preparation parameters like growth rate or plasma composition.

In previous works we studied the preparation of a-Si:H by electron cyclotron resonance microwave plasma assisted evaporation. It was shown that the substrate temperature modifies the hydrogen bonding ${ }^{6}$ and that bombardment by ions accelerated by a moderate voltage $(200 \mathrm{~V})$ could strongly densify the film structure without changing the hydrogen bonding type. ${ }^{7}$ We also demonstrated that there is a mass effect of the ions since the densification of the films is easier with a deuterium plasma than with a hydrogen plasma. ${ }^{7}$ In order to improve the preparation, films were made with a plasma composed of hydrogen and heavy ions such as argon. This article discusses the influence of the

${ }^{\text {a)} E l e c t r o n i c ~ m a i l: ~ r i n n e r t @ 1 p s . u-n a n c y . f r ~}$ substrate temperature on these films and we show that it is possible to obtain high quality a-Si:H films with very good stability against light exposure.

\section{EXPERIMENT}

The plasma generation chamber and the growth chamber were evacuated by a cryogenerator with a pumping rate of $1000 \ell / \mathrm{s}$. The background pressure was $10^{-8}$ Torr. Silicon was evaporated from an electron beam gun and the deposition rate $(1 \AA / s)$ was monitored and controlled by a quartz microbalance system. An electron cyclotron resonance (ECR) plasma source was used to generate the ion beam. The $2.45 \mathrm{GHz}$ microwave energy of the ECR source was $200 \mathrm{~W}$. A $875 \mathrm{G}$ axial magnetic field was used to create ECR and to promote efficient coupling of the microwaves to the plasma. The hydrogen-argon mixture was prepared before deposition in the proportion of 1:1 and the flow in the ion source was regulated by maintaining the total pressure in the evaporation chamber at $4 \times 10^{-5}$ Torr. The samples were deposited on (111) Si substrates for thermal desorption spectrometry (TDS) experiments and infrared-absorption measurements, on Corning glass 7059 for conductivity and photoconductivity studies. Samples were prepared with different substrate temperatures equal to $120^{\circ} \mathrm{C}, 180^{\circ} \mathrm{C}, 240{ }^{\circ} \mathrm{C}$, and $300{ }^{\circ} \mathrm{C}$.

The microstructure of the films was both studied by infrared (IR)-absorption measurements and by thermal desorption spectroscopy (TDS). The hydrogen bonding configuration was obtained from Fourier transform infrared transmission measurements using a Perkin-Elmer 2000 spectrometer with a resolution of $4 \mathrm{~cm}^{-1}$. The contribution of an uncoated reference silicon substrate was subtracted from the experimental spectra. The thermal stability of hydrogen was studied by TDS. The films were inserted into a quartz tube evacuated by an ionic pump allowing a base pressure of $2 \times 10^{-8}$ Torr in the chamber and were heated at a constant rate of $10^{\circ} / \mathrm{min}$ to $800{ }^{\circ} \mathrm{C}$. The gaseous components desorbing from the surface were ionized and detected by a quadrupole mass analyzer. The dark conductivity $\left(\sigma_{\mathrm{d}}\right)$ and photoconductivity $\left(\sigma_{\mathrm{ph}}\right)$ under a $400 \mathrm{~mW} / \mathrm{cm}^{2}$ illumina- 
TABLE I. Conductivity and photoconductivity measurements for samples prepared at different substrate temperatures.

\begin{tabular}{cccr}
\hline \hline $\begin{array}{c}\text { Substrate temperature } \\
\left({ }^{\circ} \mathrm{C}\right)\end{array}$ & $\mathrm{E}_{\mathrm{a}}(\mathrm{eV})$ & $\sigma_{\text {dark }}(300 \mathrm{~K})(\Omega \mathrm{cm})^{-1}$ & $\mathrm{R}_{\mathrm{ph}}$ \\
\hline 120 & 0.74 & $1 \times 10^{-9}$ & 6900 \\
180 & 0.73 & $1.9 \times 10^{-9}$ & 2200 \\
240 & 0.74 & $1.1 \times 10^{-9}$ & 800 \\
300 & 0.22 & $2.8 \times 10^{-5}$ & 1 \\
\hline
\end{tabular}

tion from a $500 \mathrm{~W}$ arc xenon lamp were measured for the samples on glass substrates using longitudinal electrode structure. To avoid undesirable temperature effects during illumination a water filter was used. Measurements were made under a $10^{-3}$ Torr vacuum to avoid atmosphere contamination which can appear in a longitudinal electrode structure. Moreover energy dispersive x-ray spectroscopy experiments showed the atomic percentage of argon in the films is inferior to 0.2 .

\section{RESULTS AND DISCUSSION}

The quality of the passivation of dangling bonds was studied by conductivity versus temperature measurements. All the samples were first heated to $190{ }^{\circ} \mathrm{C}$ in order to desorb the surface gaseous contamination and measurements of the conductivity were made between $190{ }^{\circ} \mathrm{C}$ and room temperature during cooling. The electronic properties of the four samples are displayed in Table I. The conductivity of samples prepared at $120^{\circ} \mathrm{C}, 180{ }^{\circ} \mathrm{C}$ and $240{ }^{\circ} \mathrm{C}$ fits perfectly the thermally activated law with an activation energy of around $0.73 \mathrm{eV}$. The dark conductivity of these samples is hardly the same in the $1 \times 10^{-9}-2.5 \times 10^{-9}(\Omega \mathrm{cm})^{-1}$ range. By contrast the sample prepared at $300{ }^{\circ} \mathrm{C}$ is quite different and fits the Mott exponential relation in $\mathrm{T}^{-1 / 4}$ with a dark conductivity equal to $2.8 \times 10^{-5}(\Omega \mathrm{cm})^{-1}$. The best fit with the Arrhenius law results in an activation energy equal to $0.22 \mathrm{eV}$, which demonstrates that contrary to the other samples, this material is characterized by a great number of defect states in the gap. The films were subjected to a light exposure of more than $10^{3} \mathrm{~min}$. The photoconductivity ratio $\sigma_{\mathrm{ph}}(0) / \sigma_{\text {dark }}$ at the beginning of the light exposure, noted $\mathrm{R}_{\mathrm{ph}}$ is listed in Table I and the evolution versus time of the normalized photoconductivity $\sigma_{\mathrm{ph}}(\mathrm{t}) / \sigma_{\mathrm{ph}}(0)$ is represented in Fig. $1 . \mathrm{R}_{\mathrm{ph}}$ is a decreasing function of the substrate temperature and decreases from 6900 for the sample prepared at $120{ }^{\circ} \mathrm{C}$ to 800 for the material prepared at $240{ }^{\circ} \mathrm{C}$. This evolution can be correlated to the hydrogen content of the films with a best passivation for the high hydrogenated films. The sample prepared at $300{ }^{\circ} \mathrm{C}$ is not a photoconductor material which is consistent with the conductivity versus temperature evolution. The photoconductivity decay behavior shows clearly a dependence on the substrate temperature. While samples prepared at $120^{\circ} \mathrm{C}$ and $180{ }^{\circ} \mathrm{C}$ present a rapid decay of the photoconductivity, the material prepared at $240{ }^{\circ} \mathrm{C}$ does not present any decay during all the exposure. Moreover the dark conductivity hardly changes during illumination for all the samples. Hence the light induced effects in these materials prepared at low temperature seem to be dif-

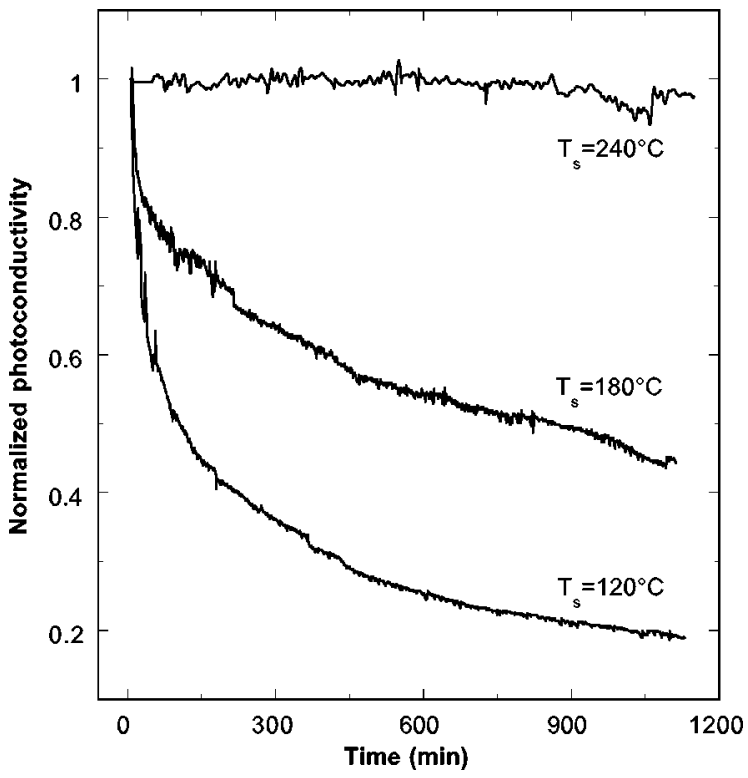

FIG. 1. Normalized photoconductivity decay under a $400 \mathrm{~mW} / \mathrm{cm}^{2}$ light exposure from an arc xenon lamp for samples prepared at different substrate temperatures.

ferent from the Staebler-Wronski effect. However light induced effects are metastable and can be removed by heating the samples to $190{ }^{\circ} \mathrm{C}$. By all appearances the light seems not to have created defects in the film prepared at $240{ }^{\circ} \mathrm{C}$. To understand the electrical properties of the films, the study of the microstructure was realized. Infrared spectrometry and thermal desorption spectrometry experiments are presented in the next sections.

The infrared absorption band at $640 \mathrm{~cm}^{-1}$ was used to calculate the hydrogen content in a-Si:H films. This band is assigned to the wagging band of $\mathrm{SiH}_{n}(n=1,2,3)$ and the integrated strength of this mode is proportional to the total hydrogen concentration. With the usual proportionally constant $1.6 \times 10^{19} \mathrm{~cm}^{-28}$ and an atomic density of silicon fixed to $5 \times 10^{22} \mathrm{~cm}^{-3}, \mathrm{C}_{\mathrm{H}}$ was estimated to $13.4 \%, 9 \%, 7.4 \%$ and $3.9 \%$, respectively, for the substrate temperatures $120^{\circ} \mathrm{C}$, $180{ }^{\circ} \mathrm{C}, 240{ }^{\circ} \mathrm{C}$ and $300{ }^{\circ} \mathrm{C}$. Infrared spectrometry spectra of these samples are represented in Fig. 2 for the 1850-2300 $\mathrm{cm}^{-1}$ range. Absorption spectra clearly show two peaks in the 2000-2100 $\mathrm{cm}^{-1}$ range. A polynomial basis line was subtracted to the spectra which were then deconvoluted by Gaussians. Table II gives the respective peaks positions, areas and microstructure parameters $\mathrm{R}$ for all the samples. $\mathrm{R}$ is defined as the ratio of the intensities of the absorption bands $\mathrm{I}_{2100} /\left[\mathrm{I}_{2100}+\mathrm{I}_{2000}\right]$ and can be related to the fraction of polyhydride groups and clustered monohydride groups. An increase in $\mathrm{R}$ is generally correlated to an increase of a density deficiency. The absorption near $2000 \mathrm{~cm}^{-1}$ is attributed to the stretching modes of $\mathrm{SiH}$ while absorption near 2100 $\mathrm{cm}^{-1}$ is ascribed to the stretching modes of $\mathrm{SiH}_{2},\left(\mathrm{SiH}_{2}\right)_{\mathrm{n}}$ and $\mathrm{SiH}_{3}$ or of $\mathrm{SiH}$ groups located at internal surfaces or microvoids. The sample prepared at $120^{\circ} \mathrm{C}$ is dominated by peaks centered at $2093 \mathrm{~cm}^{-1}$ and at $2014 \mathrm{~cm}^{-1}$. Small bands appear at 2175 and $2246 \mathrm{~cm}^{-1}$ which can be attributed to $\mathrm{SiH}$ and $\mathrm{SiH}_{2}$ configurations containing oxygen atoms in their back bonds. This oxygen contamination, also visible at 


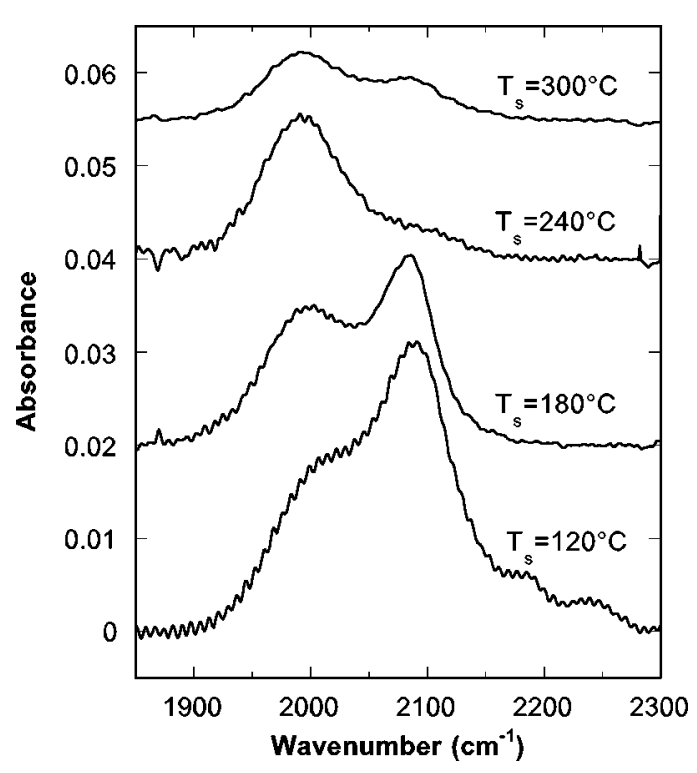

FIG. 2. Infrared absorption spectra of samples prepared at different substrate temperatures $\mathrm{T}_{\mathrm{s}}$.

the $1050 \mathrm{~cm}^{-1}$ absorption band, appears after exposure to atmosphere and is an indication of the microvoids' rich structure-characteristic of films prepared at low temperature. This sample presents an absorption spectrum characteristic of poor electronic quality a-Si:H film. A shift of the peak near $2000 \mathrm{~cm}^{-1}$ is observed as the substrate temperature increases. According to a recent work ${ }^{9}$ this displacement to the lower frequencies is presumably due to a decrease of the hydrogen content and not to a modification in the bonding type. The contribution of the band near $2100 \mathrm{~cm}^{-1} \mathrm{de}-$ creases as a function of the substrate temperature in the range $120-240{ }^{\circ} \mathrm{C}$ and it increases for $\mathrm{T}_{\mathrm{s}}=300{ }^{\circ} \mathrm{C}$. Hydrogen bonding in the sample prepared at $240{ }^{\circ} \mathrm{C}$ is principally composed of monohydride groups with a structure parameter equal to 0.2 , while this latter is equal to 0.45 for the sample prepared at $120^{\circ} \mathrm{C}$ and 0.37 for the film elaborated at $300{ }^{\circ} \mathrm{C}$, which suggests there is an optimum in the substrate temperature to obtain a $\mathrm{SiH}$ film free from polyhydride groups. In our experiments, the best microstructure parameter was obtained at $240{ }^{\circ} \mathrm{C}$. It is also important to notice the great influence of the argon ions on the bonding type. They allow us to produce a material dominated by $\mathrm{SiH}$ bonds

TABLE II. Properties of a-Si:H samples deduced from infrared absorption measurements.

\begin{tabular}{ccccc}
\hline \hline $\begin{array}{c}\text { Substrate } \\
\text { temperature }\end{array}$ & $\begin{array}{c}\text { Peak } \\
\text { position }\left(\mathrm{cm}^{-1}\right)\end{array}$ & $\begin{array}{c}\text { Peak area } \\
\text { (arb. units) }\end{array}$ & $\mathrm{R}$ & $\mathrm{C}_{\mathrm{H}}$ (at \%) \\
\hline \multirow{2}{*}{120} & 2014 & 2.0 & 0.47 & 13.4 \\
& 2093 & 1.8 & & \\
& 2175 & 0.5 & & \\
\multirow{2}{*}{180} & 2246 & 0.1 & & \\
& 2001 & 1.5 & 0.42 & 9 \\
240 & 2085 & 1.1 & & \\
& 1991 & 1.2 & 0.20 & 7.4 \\
300 & 2084 & 0.3 & & \\
& 1992 & 0.6 & 0.33 & 3.9 \\
\hline \hline
\end{tabular}

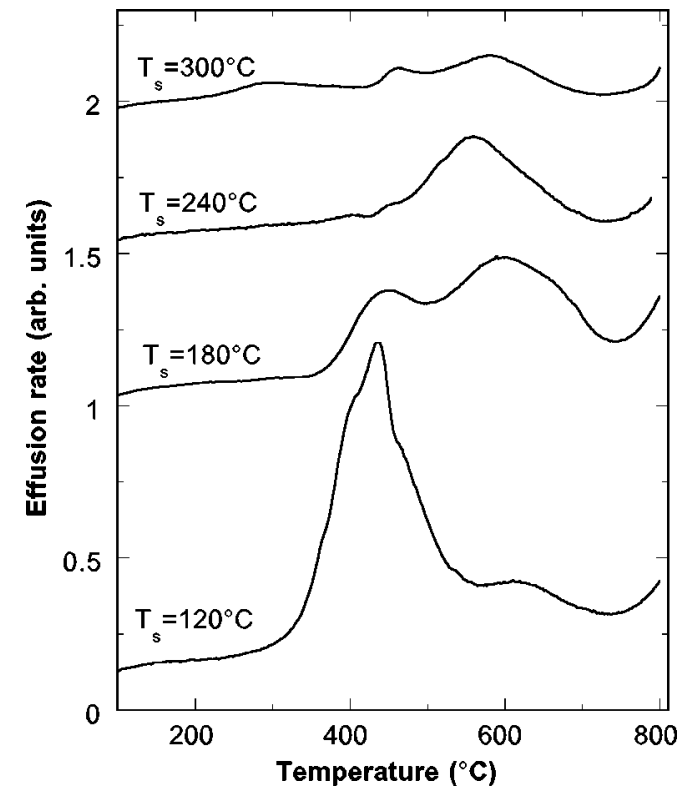

FIG. 3. Thermal desorption spectroscopy spectra for samples prepared at different substrate temperatures $T_{\mathrm{s}}$.

which was not the case with a pure hydrogen plasma, ${ }^{6}$ since the corresponding sample prepared at $240{ }^{\circ} \mathrm{C}$ has a microstructure factor equal to 0.55 .

The hydrogen effusion spectra of the four samples are represented in Fig. 3. The spectrum of the sample prepared at $120{ }^{\circ} \mathrm{C}$ is dominated by a peak at $440{ }^{\circ} \mathrm{C}$ which is usually attributed to the desorption of hydrogen localized in the internal microvoids. A low density a-Si:H film composed of a large interconnected voids network generally presents a unique effusion peak near $400{ }^{\circ} \mathrm{C}$. A weak component at $600{ }^{\circ} \mathrm{C}$ is attributed to the effusion of hydrogen limited by a diffusion process. ${ }^{10}$ This contribution of the diffusion peak at high temperature increases as a function of the substrate temperature in the $120-240^{\circ} \mathrm{C}$ range. The effusion spectrum of the samples prepared at $180^{\circ} \mathrm{C}$ is dominated by the diffusion peak but still presents a desorption peak at low temperature. However the sample elaborated at $240{ }^{\circ} \mathrm{C}$ is characterized by a unique high temperature peak. Such an effusion spectrum is typical from a dense material free from microvoids and with stable $\mathrm{SiH}$ bonds. The effusion spectrum of the sample elaborated at $300{ }^{\circ} \mathrm{C}$ presents very weak peaks. It is similar to the sample prepared at $180^{\circ} \mathrm{C}$ with a dominating diffusion peak at $580{ }^{\circ} \mathrm{C}$. We demonstrate the high temperature peak is a diffusion peak by measuring the film thickness dependence. Indeed if diffusion limits the evolution rate, the rising diffusion length with increasing film thickness will result in a shift of the evolution peak to higher temperatures. The temperature of this peak increases from $560{ }^{\circ} \mathrm{C}$ to $585^{\circ} \mathrm{C}$ when the thickness increases from $2000 \AA$ to $4000 \AA$. The TDS study demonstrates that the stability of hydrogen is improved by increasing the substrate temperature below a maximum and that the material is certainly denser and free from voids. By analyzing these results with regard to the infrared experiments, the diffusion peak seems to be correlated to the absorption peak at $2000 \mathrm{~cm}^{-1}$. Still it would be hazardous to attribute the desorption peak to the $\mathrm{SiH}_{2}$ groups and the dif- 
fusion peak to the $\mathrm{SiH}$ groups. In fact hydrogen from both $\mathrm{SiH}$ and $\mathrm{SiH}_{2}$ configurations desorbs from the interconnected voids at around $400{ }^{\circ} \mathrm{C}$ and diffuses throughout the bulk around $600{ }^{\circ} \mathrm{C}$. The correlation between the absorption peak at $2000 \mathrm{~cm}^{-1}$ and the diffusion peak is essentially due the fact that on the one hand the high substrate temperature promotes monohydride groups and on the other hand the high substrate temperature combined with the argon influence densifies the material and then promotes the diffusion phenomenon. With the use of argon-hydrogen plasma the samples prepared at $240{ }^{\circ} \mathrm{C}$ present the hydrogen bonding and the hydrogen stability of the best material prepared by the traditional glow discharge technique.

The stability to light exposure is correlated to the microstructural quality of the films. Indeed the sample with high hydrogen stability and with a weak number of polyhydride groups, assumed to be a dense material without microvoids, presents high stability to light exposure. On the contrary the light induced photoconductivity decay in the other samples prepared at lower substrate temperature is an increasing function of the microstructure parameter and of the quantity of hydrogen weakly thermally stable. The materials prepared at $120^{\circ} \mathrm{C}$ and $180^{\circ} \mathrm{C}$ are presumably voids rich with polyhydride groups. These results support existing models proposed to describe the light induced effect. ${ }^{11,12}$ Carlson suggested a mechanism involving the motion of hydrogen on the surfaces of microvoids and Yonezawa showed in a theoretical study that in a-Si:H films the weak $\mathrm{Si}-\mathrm{Si}$ bonds can be weakened further by neighboring $\mathrm{Si}-\mathrm{H}$ bonds and then be broken by light exposure. We believe the degradation of our materials is first due to the weak bonds breaking process, improved by an increasing microstructure parameter, ${ }^{13}$ and to the creation of metastable $\mathrm{Si}-\mathrm{H}$ bonds allowed by the motion of hydrogen in the low dense amorphous network.

\section{CONCLUSION}

In summary, photoconductor a-Si:H thin films were prepared by the ion-beam-assisted evaporation method with a hydrogen-argon plasma. We believe that the heavy argon atoms contribute to densify the a-Si:H films while temperature has a strong influence on the hydrogen bonding. The best sample obtained for $\mathrm{T}_{\mathrm{s}}=240{ }^{\circ} \mathrm{C}$ is characterized by a high diffusion peak temperature in the TDS spectrum and by hydrogen bonding strongly dominated by $\mathrm{Si}-\mathrm{H}$ bonds. In good agreement with the traditional bond breaking model, this high quality material, which has a dense amorphous network with stable $\mathrm{Si}-\mathrm{H}$ bonds, is very stable to light exposure.

${ }^{1}$ D. L. Staebler and C. R. Wronski, Appl. Phys. Lett. 31, 292 (1977).

${ }^{2}$ M. Stutzmann, W. B. Jackson, and C. C. Tsai, Phys. Rev. B 32, 23 (1985).

${ }^{3}$ M. Vergnat, G. Marchal, and Ph. Mangin, J. Non-Cryst. Solids 137\&138, 907 (1991).

${ }^{4}$ V. Grasso, A. M. Mezzasalma, and F. Neri, Solid State Commun. 41, 675 (1982).

${ }^{5}$ M. Shindo, S. Sato, I. Myokan, S. Mano, and T. Shibata, J. Non-Cryst. Solids 59\&60, 747 (1983).

${ }^{6}$ N. Hadj Zoubir, H. Rinnert, M. Vergnat, G. Marchal, and A. Burneau, Nucl. Instrum. Methods Phys. Res. B 112, 263 (1996).

${ }^{7}$ H. Rinnert, M. Vergnat, G. Marchal, and A. Burneau, Appl. Phys. Lett. 69, 1582 (1996)

${ }^{8}$ H. R. Shanks, C. J. Fang, L. Ley, M. Cardona, F. J. Demond, and S. Kalbitzer, Phys. Status Solidi B 100, 43 (1980).

${ }^{9}$ J. Daey Ouwens and R. E. I. Schropp, Mater. Res. Soc. Symp. Proc. 377, 419 (1995).

${ }^{10}$ W. Beyer, Physica B 170, 105 (1991).

${ }^{11}$ D. E. Carlson, Appl. Phys. A: Solids Surf. 41, 305 (1986).

${ }^{12}$ F. Yonezawa, S. Sakamoto, and M. Hori, J. Non-Cryst. Solids 137\&138, 135 (1991).

${ }^{13}$ E. Bhattacharya and A. H. Mahan, Appl. Phys. Lett. 52, 1587 (1988). 